\title{
Contrast-enhanced harmonic endoscopic ultrasound-guided drainage of a postoperative pancreatic fistula
}

The effectiveness of endoscopic ultrasound (EUS)-guided drainage of a postoperative pancreatic fistula (POPF) has been reported [ $1-3]$. It is sometimes difficult to distinguish a POPF from surrounding organs and tissues because echogenicity of necrotic or infected tissue becomes as high as that of surrounding tissue in a POPF. Contrast-enhanced harmonic EUS (CH-EUS) may help to identify the spread of a POPF. Here, we present a video case of $\mathrm{CH}$-EUS-guided drainage of a POPF after pancreaticoduodenectomy.

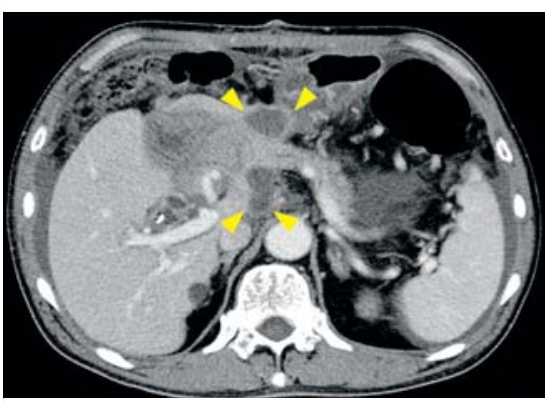

- Fig. 1 Contrast-enhanced computed tomography showed that there was fluid collection around the pancreas (yellow arrowheads).
A 66-year-old man with bile duct cancer underwent pancreaticoduodenectomy at our hospital. Eighteen days later, he developed abdominal pain and high fever due to POPF. Contrast-enhanced computed tomography detected a POPF $(50 \times 25 \mathrm{~mm})$ around the pancreas ( $\triangleright$ Fig.1). We attempted EUS-guided drainage; however, the spread of the POPF could not be identified by fundamental B-mode EUS. There was no anechoic lesion, but a high echoic area around the pancreas. Therefore, we performed $\mathrm{CH}$-EUS to identify the spread of the POPF. Fifteen seconds after infusion of $0.7 \mathrm{~mL}$ contrast agent, the avascular area of the high echoic area was identified in a CH-EUS image ( - Video 1). The POPF was punctured using a 19-gauge needle under CH-EUS, and its lumen was recognized by injecting contrast medium via this needle. A 0.025 -inch guidewire was inserted through the needle and coiled into the POPF. The needle was withdrawn and the guidewire was left inside the POPF. A 7-Fr endoscopic nasobiliary drainage tube was deployed into the POPF for drainage.
Abdominal pain improved and the size of the POPF and amount of pancreatic juice drained via the external tube decreased ( $\triangleright$ Fig.3). Ten days later, we cut the external drainage tube, dropped it into the stomach ( $\triangleright$ Fig. 4 ), and used it as an internal catheter for POPF drainage because clinical improvement had been observed.

Endoscopy_UCTN_Code_TTT_1AS_2AD

Competing interests

None

The authors

Takashi Tamura', Masayuki Kitano', Manabu Kawai $^{2}$, Masahiro Itonaga ${ }^{1}$, Ken-ichi Okada ${ }^{2}$, Hiroki Yamaue ${ }^{2}$

1 Second Department of Internal Medicine, Wakayama Medical University, Wakayama, Japan

2 Second Department of Surgery, Wakayama Medical University, Wakayama, Japan
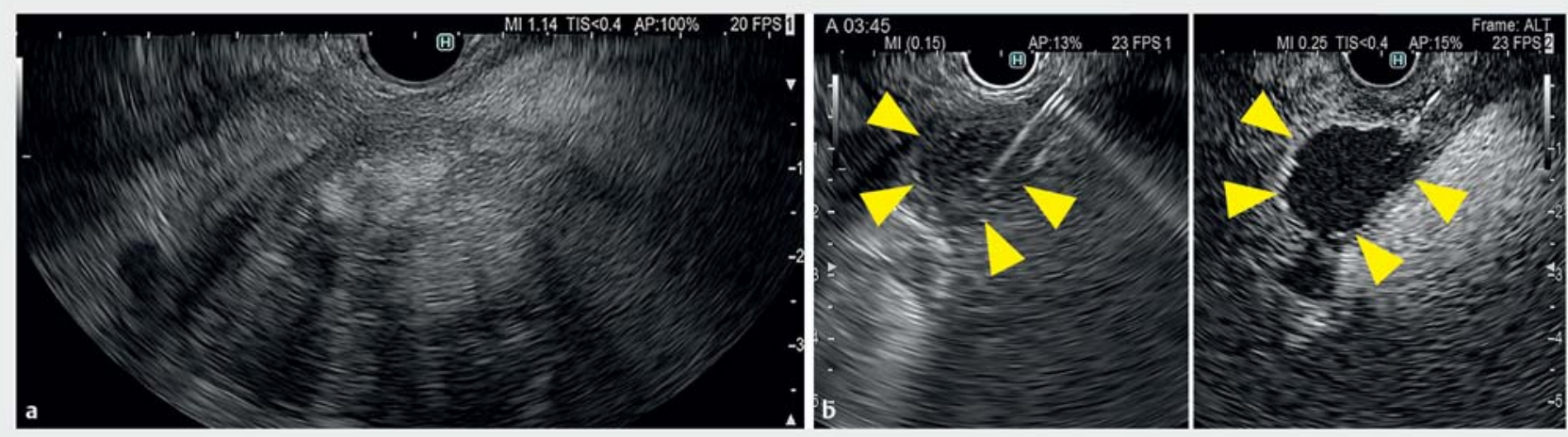

- Fig. 2 Endoscopic ultrasound images. a A heterogeneous high echoic area without anechoic lesion was observed on a fundamental B-mode image. b An avascular area with a sharp margin (yellow arrowheads) was seen on a contrast-enhanced harmonic image. The postoperative pancreatic fistula was punctured with a 19-gauge needle under guidance of contrast-enhanced harmonic endoscopic ultrasound. 


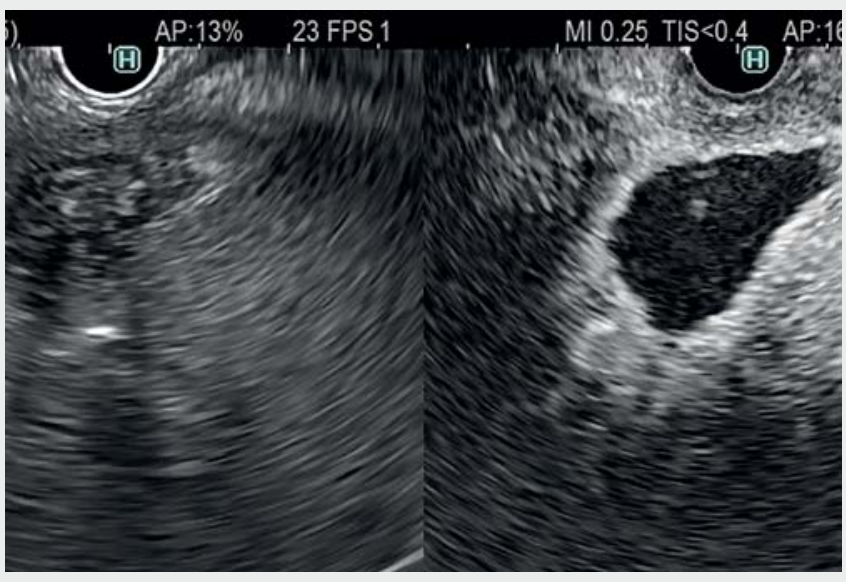

Video 1 Contrast-enhanced harmonic endoscopic ultrasound-guided drainage of a postoperative pancreatic fistula.

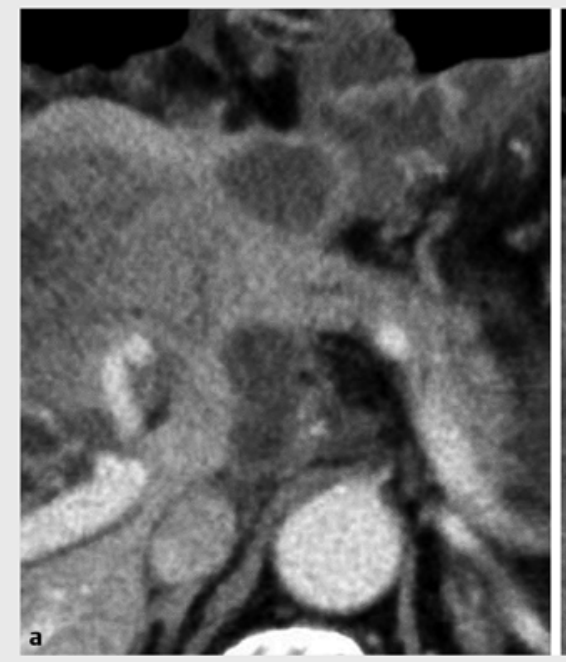

- Fig. 3 Contrast-enhanced computed tomography images. a Before endoscopic ultrasound (EUS)-guided drainage, showing fluid collection around the pancreas. $\mathbf{b}$ At 10 days after performing EUS-guided drainage, showing that the fluid collection around the pancreas had resolved.

Corresponding author

\section{Masayuki Kitano, MD, PhD}

Second Department of Internal Medicine,

Wakayama Medical University, 811-1

Kimiidera, Wakayama City, Wakayama

641-8509, Japan

Fax: +81-73-4453616

kitano@wakayama-med.ac.jp
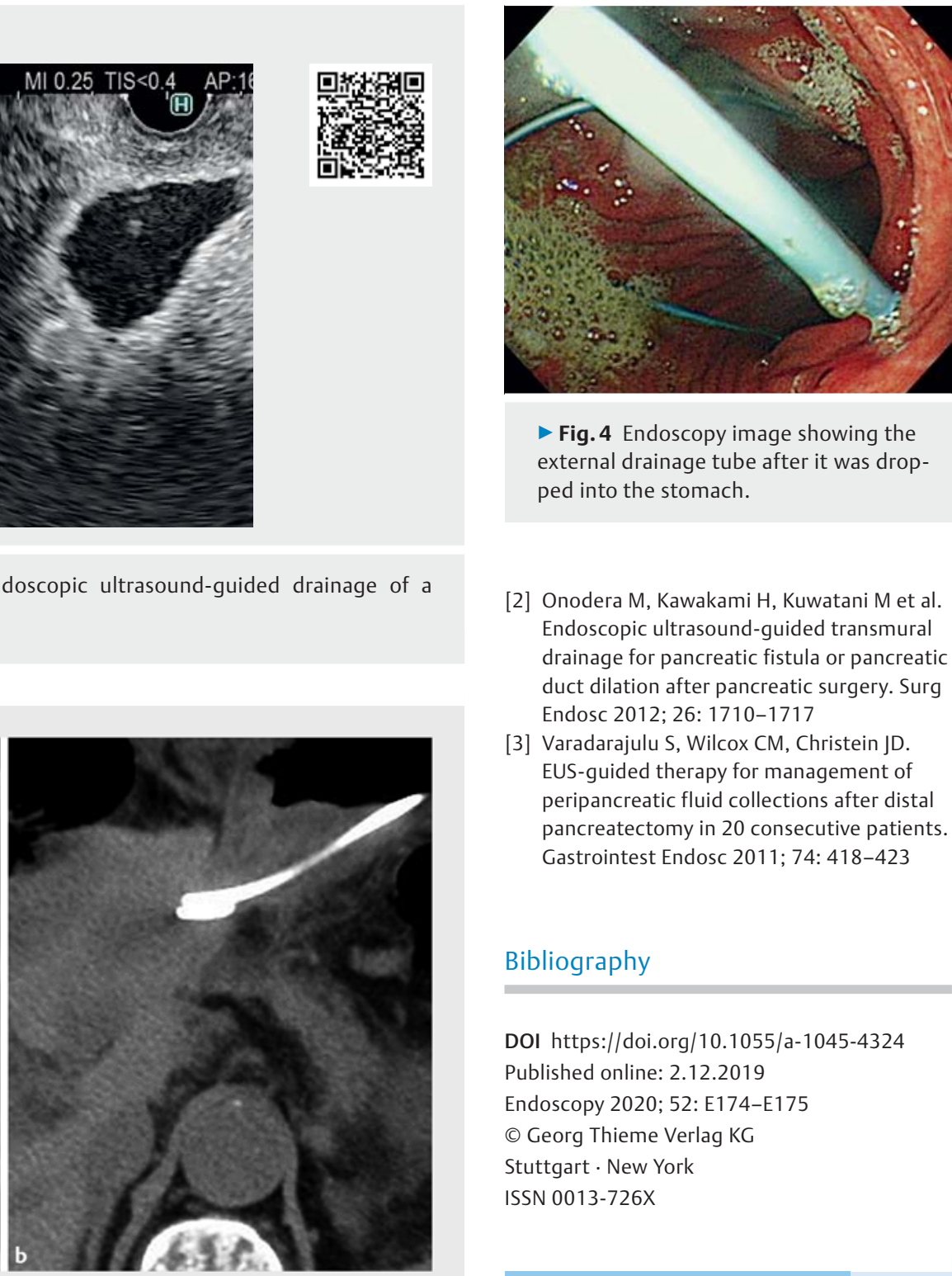

- Fig. 4 Endoscopy image showing the external drainage tube after it was dropped into the stomach.

[2] Onodera M, Kawakami H, Kuwatani M et al. Endoscopic ultrasound-guided transmural drainage for pancreatic fistula or pancreatic duct dilation after pancreatic surgery. Surg Endosc 2012; 26: 1710-1717

[3] Varadarajulu S, Wilcox CM, Christein JD. EUS-guided therapy for management of peripancreatic fluid collections after distal pancreatectomy in 20 consecutive patients. Gastrointest Endosc 2011; 74: 418-423

\section{Bibliography}

DOI https://doi.org/10.1055/a-1045-4324

Published online: 2.12 .2019

Endoscopy 2020; 52: E174-E175

(c) Georg Thieme Verlag KG

Stuttgart · New York

ISSN 0013-726X

\section{ENDOSCOPY E-VIDEOS}

https://eref.thieme.de/e-videos

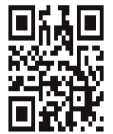

Endoscopy E-Videos is a free access online section, reporting D. on interesting cases and new techniques in gastroenterological endoscopy. All papers include a high quality video and all contributions are freely accessible online. Management of peripancreatic fluid collections following partial pancreatectomy: a comparison of percutaneous versus EUSguided drainage. Surg Endosc 2013; 27: $2422-2427$
This section has its own submission website at

https://mc.manuscriptcentral.com/e-videos 